Article

\title{
The Abrasive Wear Resistance of the Segmented Linear Polyurethane Elastomers Based on a Variety of Polyols as Soft Segments
}

\author{
Konrad Kwiatkowski ${ }^{1, *}$ and Małgorzata Nachman ${ }^{2}$ \\ 1 Department of Mechanics and Machine Design Fundamentals, \\ West Pomeranian University of Technology Szczecin, Al. Piastów 19, 70-310 Szczecin, Poland \\ 2 Institute of Materials Science and Engineering, West Pomeranian University of Technology Szczecin, \\ Al. Piastów 19, 70-310 Szczecin, Poland; Malgorzata.Nachman@zut.edu.pl \\ * Correspondence: Konrad.Kwiatkowski@zut.edu.pl; Tel.: +48-506-017-681
}

Received: 19 November 2017; Accepted: 6 December 2017; Published: 12 December 2017

\begin{abstract}
The presented results make an original contribution to the development of knowledge on the prediction and/or modeling of the abrasive wear properties of polyurethanes. A series of segmented linear polyurethane elastomers (PUR) - In which the hard segments consist of 4,4'-methylene bis(phenylisocyanate) and 1,4-butanodiol, whilst polyether, polycarbonate, or polyester polyols constitute the soft segments-Were synthesized and characterized. The hardness and wear performance as functions of the variable chemical composition of polyurethane elastomers were evaluated in order to define the relationship between studied factors. The microstructure was characterized in detail, including analysis of the hydrogen bonding by Fourier transformed infrared (FT-IR) spectroscopy and the phase structure by X-ray scattering (WAXS) and differential scanning calorimetry (DSC) methods. The presented studies provide the key features of the polymer composition affecting the abrasive resistance as well as attempts to explain the origin of the differences in the polyurethane elastomers' performance.
\end{abstract}

Keywords: polyurethane elastomers; PUR; abrasive wear; microstructure

\section{Introduction}

The literature data state quite clearly that, on the basis of the specific mechanical properties of the materials, it is possible to predict the performance and durability of the final product; however, there is an exception-The determination of the wear properties in friction pairs [1-7]. The huge number of the possible variants of friction pairs and the operating features have not yet allowed the creation of an effective recipe for the prediction of the wear intensity of the friction elements.

The prediction and/or modeling of the wear properties of the synthetic materials, especially polyurethane elastomers (PUR), is particularly difficult, mostly due to the wide variation in their properties [8-13]. The use of various raw materials, variable chemical composition, or application of different production methods and further processing methods gives a chance to produce PUR with widely varied properties. In general, the overall mechanical properties of PUR can be quite easily tailored by the thought-out selection of the components, composition, and preparation conditions [14-17]. For example: The hardness of the final product mainly depends on the content of the hard segments (HS) in the polyurethane. The hardness of the material is higher when the content of the HS is higher. However, in the literature there is a lack of data which could facilitate the prediction and/or modeling of the wear properties of PUR. This extensive research problem is very essential, mainly due to the fact that PUR offer an outstanding abrasive wear resistance when compared with rubbers, plastics, or even metals, and are therefore widely used in the tribological systems where a high 
abrasion resistance is required. For example: conveyor belt cleaning systems (PU scrapers), vibrating screens (PU sieves), or wheels for heavy duty vehicles, but also in the most severe applications of the aerospace and military industries, and so on $[14,16]$.

Wear and friction are much better understood for metals than they are for polymers. Therefore, researchers try to make direct applications of metal friction and wear to polymers $[6,7,10,18]$. Applying the results from the wear of metals to polymers suggested that abrasive wear should be related to the hardness [10]. Therefore, the users of PUR are convinced that there is a relationship between the hardness and the abrasion resistance, or, more precisely, if the material has higher hardness, then it is more resistant to abrasive wear. Unfortunately, the literature data do not quite clearly specify this dependency. Zygmunt Wirpsza in his scientific work [14], confirmed the validity of the relationship quoted above.

However, the results obtained in the other abrasion characteristics studies [19-22] demonstrate a completely different relationship-The abrasive wear resistance of PUR increases along with the content of soft segments (SS), i.e., the elastomers with lower hardness were more resistant to abrasive wear. Nevertheless, the results obtained in our preliminary study [23] showed that the polyurethane elastomers, despite having the same hardness, can differ significantly in their abrasion resistance. It has been shown that the differences in the abrasive wear are substantial (up to 20 times more for materials with the same hardness). The differences in the abrasion resistance are most likely caused by the various components used in the preparation of the final product. This means that the most important factor in the wear resistance of PUR is not their macroscopic hardness but the chemical structure and the resulting morphology.

The segmented chemical structural composition of PUR is the specific structural feature which strongly influences their properties [14-17]. The molecular structure of PUR is quite complicated. They phase separate during the polymerization reaction, forming a supermolecular structure [24-27]. Moreover, structural units of various forms and sizes develop during the reaction [28-30]. In this study, the microphase-separated structure is analyzed.

The polyurethane chain is composed of the HS and the SS. In most of the polyurethanes, the phase segregation occurs due to the incompatibility (different polarity and chemical nature) between these segments. The SS are composed of polyols which may differ in chemical structure, molecular weight, or functionality. The HS are obtained from isocyanates and low-molecular-weight chain extenders. Practically, only a few isocyanates are used, with 4,4-diphenylmethane diisocyanate (MDI) and toluene diisocyanate (TDI) used most frequently [31]; therefore, it is most likely the chemical structure of the SS that is the most important factor influencing the abrasive wear resistance of the polyurethane elastomers. Although the effect of the chemical structure of the components on the mechanical properties of the polyurethane elastomers has been investigated extensively [32-35], the effect of the chemical composition and the resulting physical structure on the abrasive wear resistance has not yet been well described [8-10,19].

In this study, a range of segmented linear polyurethane elastomers were synthesized with polyether, polycarbonate, and polyester polyols as soft segments. All polyols were characterized by the molecular weight of $2000 \mathrm{~g} / \mathrm{mol}$. The HS consisted of 4,4'-methylene bis (phenylisocyanate) (MDI) and 1,4-butanodiol (1,4-BD). The stoichiometric ratio of the isocyanate and hydroxyl groups (NCO/OH ratio) was kept constant. The series of polyurethane elastomers based on the polyether polyol were synthesized with different concentrations of the polyether soft segments in order to assess the relationship between the hardness and the abrasive wear resistance. Additionally, one series of the samples was prepared using a diamine chain extender.

The obtained materials were analyzed for the density, hardness, and abrasive wear resistance. The morphology was characterized by wide-angle X-ray scattering (WAXS), differential scanning calorimetry (DSC), and by Fourier transformed infrared (FT-IR) spectroscopy, the latter being one of the main methods used to describe phase separation in PUR [36-40]. The differences in the chemical 
structure resulted in the varied physical structure of the polyurethane elastomers and, therefore, in strongly affected wear properties.

\section{Materials and Experimental Methods}

\subsection{Materials and Synthesis}

The series of the segmented linear PUR were synthesized using a two-step polymerization method, following the same procedure and conditions as described previously [21]. The first stage of the synthesis involved the preparation of a prepolymer by mixing polyol and isocyanate (with $6 \mathrm{wt} \%$ excess) to produce an isocyanate-terminated molecule. In the second stage, a diol or diamine chain extender was added to the prepolymer. Consequently, the polymerization takes place, and produces a multi-block copolymer. A schematic representation of the reaction and the synthesis process using a two-step polymerization method is shown in Figure 1.

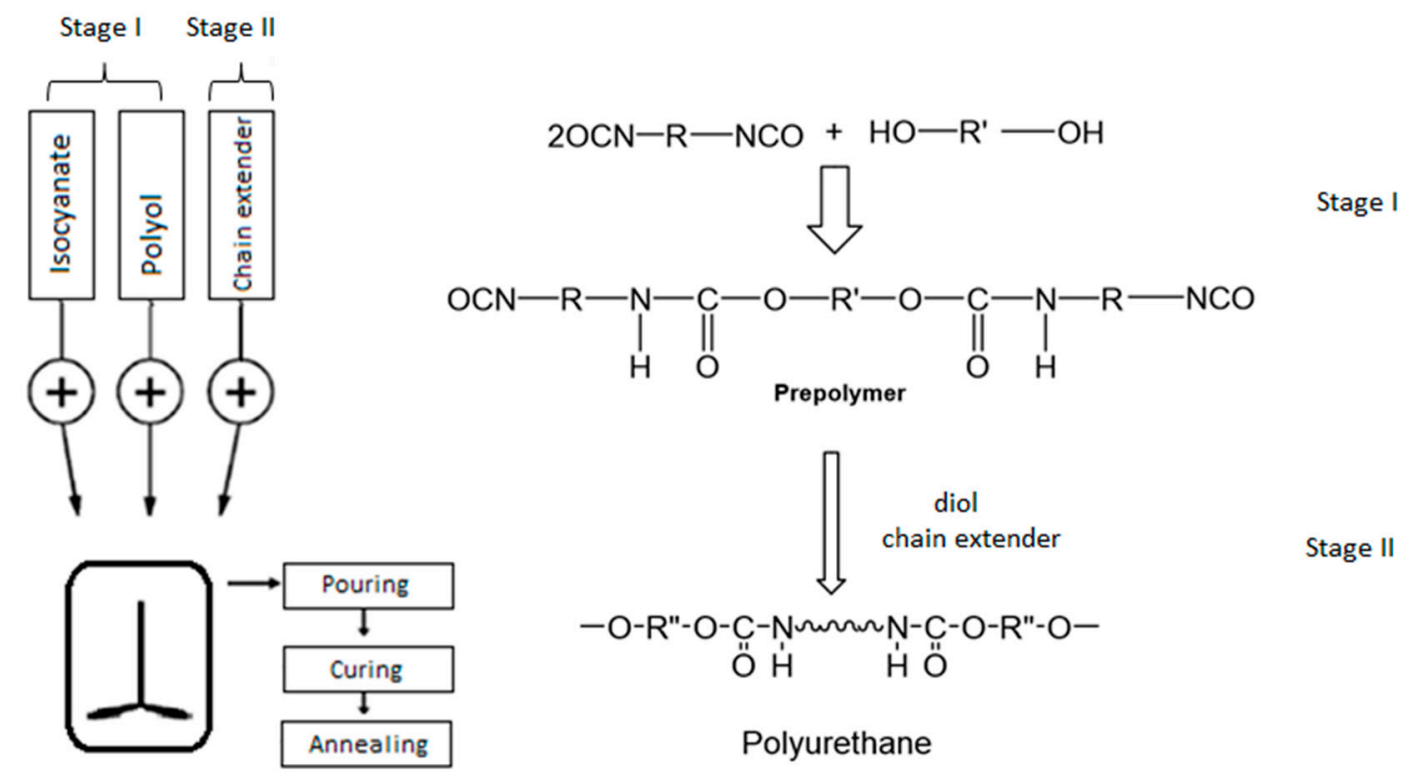

Figure 1. Schematic representation of the synthesis process and the reaction using a two-step polymerization method.

As the soft segments, three different linear polyols with various chemical structures were used: the polyether polyol, which was poly(tetramethylene-oxide) (PTMO Terathane ${ }^{\circledR} 2000$, DuPont, Wilmington, DE, USA); the polycarbonate polyol (Desmophen ${ }^{\circledR}$ C 2200, Bayer, Leverkusen, Germany); and the polyester polyol, based on polyethylene glycol and adipic acid (Polios 60/20, Purinova, Bydgoszcz, Poland). All polyols were characterized by the molecular weight of $2000 \mathrm{~g} / \mathrm{mol}$. The HS consisted of 4,4'-methylene bis (phenylisocyanate) (MDI, Sigma-Aldrich, St. Louis, MO, USA) and 1,4-butanodiol (BD, DuPont, Wilmington, DE, USA). A series of poly(ether-urethane)s was synthesized with different concentrations of the polyether SS: 50, 55, 60, 65, 70 wt \%. Additionally, one series of the samples was prepared using diamine chain extender-4,4'-methylenebis(2-chlorobenzenamine) (MOCA, Sigma-Aldrich, St. Louis, MO, USA). The molecular structures and detailed specifications of the raw materials are provided in Table 1. The stoichiometric ratio of the isocyanate and hydroxyl groups ( $\mathrm{NCO} / \mathrm{OH}$ ratio) was kept constant- 1.05 in all materials.

The synthesized materials were placed into a mould and left to cure at room temperature for $24 \mathrm{~h}$. Prior to annealing, all samples were heated at $60 \pm 5^{\circ} \mathrm{C}$ for $2 \mathrm{~h}$ in order to complete the reaction. The annealing was conducted for $2 \mathrm{~h}$ at the temperature of $100 \pm 5^{\circ} \mathrm{C}$. The samples were cooled to room temperature and conditioned for two weeks before the tests. The compositions, the reactants' molar ratio, and the hardness of the prepared PUR are listed in Table 2. 
Table 1. Molecular structure and detailed specifications of the raw materials used for the synthesis.

\begin{tabular}{|c|c|c|c|c|}
\hline Raw materials & Molecular structure & $\begin{array}{c}\text { Molecular } \\
\text { weight, } \mathrm{g} / \mathrm{mol}\end{array}$ & $\begin{array}{l}\text { Hydroxyl value, } \\
\text { mg KOH/g }\end{array}$ & $\begin{array}{c}\text { Melting } \\
\text { temperature, }{ }^{\circ} \mathrm{C}\end{array}$ \\
\hline $\begin{array}{l}\text { Polyether, Terathane }{ }^{\circledR} \\
2000(\text { PTMO) }\end{array}$ & $\mathrm{H}_{2}-\mathrm{CH}_{2}-\mathrm{CH}_{2}-\mathrm{CH}_{2}$ - $_{\mathrm{n}} \mathrm{OH}$ & 2000 & $53.4-59.1$ & $28-40$ \\
\hline $\begin{array}{c}\text { Polycarbonate, } \\
\text { Desmophen }{ }^{\circledR} \text { C } 2200\end{array}$ & $\mathrm{HO}-\mathrm{R}$ & 2000 & $53-59$ & $39-52$ \\
\hline Polyester, Polios $60 / 20$ & $-R-O f_{n} H$ & 2000 & $54-58$ & $40-53$ \\
\hline Diisocyanate, $4,4^{\prime}-\mathrm{MDI}$ & & 250 & - & $38-42$ \\
\hline 1,4-butanodiol, BD & & 90 & - & 20.4 \\
\hline Diamine, MOCA & & 267 & - & 102-107 \\
\hline
\end{tabular}

Table 2. Summary of the prepared polyurethane elastomers' (PUR) chemical composition and hardness, and the reactants' molar ratio.

\begin{tabular}{ccccc}
\hline Materials & Composition & $\begin{array}{c}\text { Molar ratio: } \\
\text { polyol/MDI/chain } \\
\text { extender }\end{array}$ & $\begin{array}{c}\text { Soft segment } \\
\text { (SS), wt \% }\end{array}$ & $\begin{array}{c}\text { Hardness, } \\
\text { ShD }\end{array}$ \\
\hline PUR_50/Ether/BD & PTMO, BD, MDI & $1.00 / 6.45 / 5.15$ & 50 & 52 \\
PUR_55/Ether/BD & PTMO, BD, MDI & $1.00 / 5.33 / 4.08$ & 55 & 47 \\
PUR_60/Ether/BD & PTMO, BD, MDI & $1.00 / 4.40 / 3.19$ & 60 & 43 \\
PUR_65/Ether/BD & PTMO, BD, MDI & $1.00 / 3.60 / 2.43$ & 65 & 38 \\
PUR_70/Ether/BD & PTMO, BD, MDI & $1.00 / 2.93 / 1.79$ & 70 & 30 \\
PUR_70/Carbonate/BD & Desmophen 2000, BD, MDI & $1.00 / 2.93 / 1.79$ & 70 & 37 \\
PUR_70/Ester/BD & Polios 60/20, BD, MDI & $1.00 / 2.93 / 1.79$ & 70 & 32 \\
PUR_70/Ester/MOCA & Polios 60/20, MOCA, MDI & $1.00 / 2.28 / 1.17$ & 70 & 32 \\
\hline
\end{tabular}

\subsection{Methods}

\subsubsection{The Abrasion Resistance}

The abrasion resistance of the test samples against mechanical action upon a surface was assessed by employing a rotating cylindrical roller device (Figure 2) in accordance with ISO 4649:2002 standards. The elastomer test specimen had a cylindrical form, $16 \pm 0.2 \mathrm{~mm}$ in diameter and $2 \mathrm{~mm}$ in height. It was fixed to slide over the abrasive sheet attached to the rotating roller. The sliding distance was $40 \mathrm{~m}$ and the sample-abrasive sheet contact pressure was $10 \pm 0.2 \mathrm{~N}$. The abrasion resistance was determined as a relative volume loss of the test sample $\left(\Delta V_{\text {rel }}\right)$ compared with the abrasive sheet calibrated using a standard reference. As the standard reference, the rubber compound No. 1 from Federal Institute for Materials Research and Testing (Berlin, Germany) was used.

The abrasive sheet was made of aluminum oxide with a grain size of 60 , and it was calibrated to a standard reference compound mass loss of between 180 and $200 \mathrm{mg}$ for an abrasion distance of $40 \mathrm{~m}$. The preparation of the abrasive sheet and its calibration using a standard reference compound was a very important part of the method. 


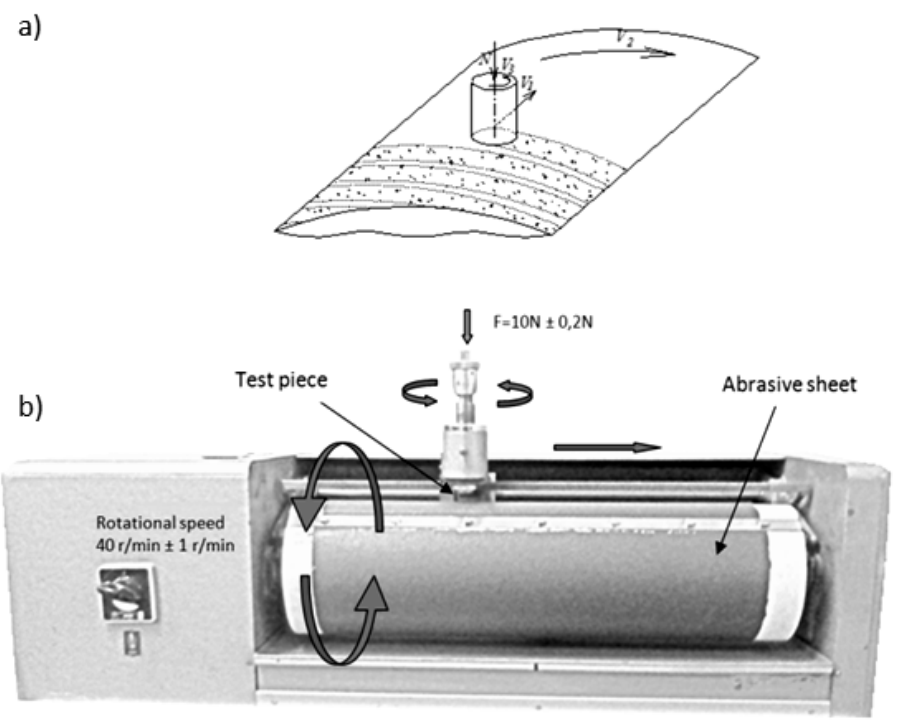

Figure 2. Schematic illustration of (a) the test sample sliding over the abrasive sheet and (b) the rotating cylindrical roller device.

After the abrasion test, the mass loss of the specimen was determined and its volume was calculated from the material's density. The volume loss of the sample was compared to the results achieved for the reference under the same test conditions. The relative volume loss $\left(\Delta V_{\text {rel }}\right)$ was calculated using the following Equation (1):

$$
\Delta V_{r e l}=\frac{\Delta m_{t} * \Delta m_{\text {const }}}{\Delta m_{r} * \rho_{t}}
$$

where $\Delta m_{t}$ is the mass loss of the analyzed sample, $\mathrm{mg} ; \Delta m_{\text {const }}$ is the defined value of the mass loss of the standard rubber sample (defined as $200 \mathrm{mg}$ ); $\Delta m_{r}$ is the arithmetic mean of the mass loss of three standard rubber samples, $\mathrm{mg}$; and $\rho_{t}$ is the density of the analyzed material, $\mathrm{mg} / \mathrm{mm}^{3}$.

\subsubsection{The Density}

Determination of the density was performed according to ISO 2781:2008.

\subsubsection{The Fourier Transform Infrared (FTIR) Spectroscopy}

The FT-IR spectra of the urethane elastomers were recorded with a Tensor-27 spectrophotometer (Bruker Optic GmbH, Ettlingen, Germany) equipped with a germanium crystal attenuated total reflectance (ATR) mode. The samples were scanned over the frequency range of $4000-400 \mathrm{~cm}^{-1}$ at the resolution of $2 \mathrm{~cm}^{-1}$. The carbonyl hydrogen-bonding index $(R)$ was determined based on the intensities of the carbonyl stretching vibrations of free $\left(A_{\text {free }}\right)$ and hydrogen-bonded $\left(A_{\text {bonded }}\right)$ groups located at 1730 and $1700 \mathrm{~cm}^{-1}$, respectively. The $R$ index was calculated according to Equation (2):

$$
R=\frac{A_{\text {bonded }}}{A_{\text {free }}}
$$

the degree of the phase separation (DPS) and the degree of the phase mixing (DPM) were obtained through Equations (3) and (4).

$$
\begin{gathered}
D P S=\frac{R}{R+1} \\
D P M=1-D P S
\end{gathered}
$$




\subsubsection{The Wide-Angle X-ray Scattering (WAXS)}

The WAXS, moreover, an investigation was made with the use of wide-angle $X$-ray diffraction analysis using a diffractometer of the Empyrean (PANalytical, Almelo, The Netherlands) type. Filtered radiation from a lamp of $\mathrm{Cu} K \alpha$ and a wavelength of $0.154 \mathrm{~nm}$ were used. The step measurement method was used with scattering angles $2 \theta$ in the range of 10 to $40^{\circ}$ and with a step size of $0.1^{\circ}$.

\subsubsection{The Differential Scanning Calorimetry (DSC)}

The thermal transitions of the investigated polymer materials were studied using the DSC technique (Q100, TA Instruments, Wilmington, DE, USA). The samples were subjected to heating-cooling-heating cycles in the temperature range of -100 to $250{ }^{\circ} \mathrm{C}$. The standard heating rate of $10^{\circ} \mathrm{C} / \mathrm{min}$ was applied. The melting temperature $\left(T_{\mathrm{m}}\right)$ was determined as the maximum of the endothermic peak, while the glass transition temperature $\left(T_{\mathrm{g}}\right)$ was set as the midpoint of the heat capacity change.

\section{Results}

The main purpose of this study was to determine the effect of both the chemical composition and microstructure of polyurethane elastomers on their abrasive wear resistance. Understanding of this relationship was crucial to selecting the optimal composition for the most wear-resistant material. In the synthesis of PUR, the aliphatic polyethers or polyesters with molecular weights of 1000-2000 g/mol are mostly used as the SS. In our previous paper [22], we proved that PUR elastomers containing ether segments of $M_{n}=1800 \mathrm{~g} / \mathrm{mol}$ revealed the higher abrasion resistance compared with PUR with ether segments of $M_{n}=1000 \mathrm{~g} / \mathrm{mol}$ and the same SS content of $60 \mathrm{wt} \%$. For that reason, the materials analyzed in this study contained oligomeric soft segments with the molecular mass of $2000 \mathrm{~g} / \mathrm{mol}$. Moreover, 1,4-butanodiol (BD) was used as the chain extender.

The results of the wear abrasive resistance were calculated as a sample volume loss after the abrasive test determined from the mass loss and density (Table 3). At first, the effects of the various chemical compositions and different contents of the ether soft segments were studied (Figure 3). When the mass content of SS is increasing within $50-70 \%$, the abrasive wear resistance is also increasing, reaching the highest value at the content of $70 \%$. From these results, we decided that subsequently synthesized PUR materials should contain $70 \mathrm{wt} \%$ of SS, and the chemical structure of the polyol was made a variable for further analysis. From Figure 3, it is clear that the polyester soft segments, reaching the value of $81 \pm 3 \mathrm{~mm}^{3}$, improve the abrasive resistance more effectively than the polyether, for which the value of $95 \pm 4 \mathrm{~mm}^{3}$ was calculated. Since the ester and carbonate groups reveal a similarity, the PUR elastomer with an aliphatic polycarbonate in the macromolecules was also included in the studies. However, its wear resistance took an intermediate position between polyester- and polyether-containing materials (Figure 4). As the additional modification in the chemical structure of the PUR samples, the diamine chain extender, MOCA, was used instead of BD. The reason for using MOCA was based on the assumption that the resulting PUR would contain the urea groups, which, compared with urethane groups, interact much more strongly with oxygen atoms. The overall results reflected in the abrasive wear resistance of PUR elastomers allowed us to determine that the most suitable composition was based on MDI, Polios $60 / 20$ as the SS with $70 \%$ mass content, and MOCA as the chain extender. The average abrasive wear resistance for this sample was $73 \pm 5 \mathrm{~mm}^{3}$. 


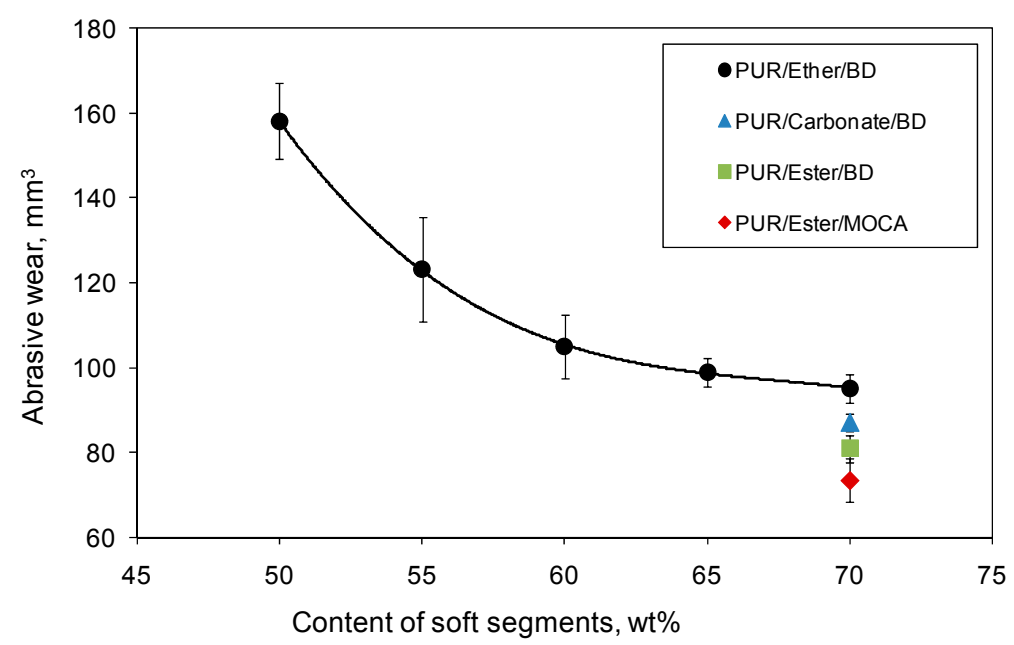

Figure 3. Abrasion wear of polyurethane elastomers (PUR) with various chemical composition and different contents of Soft Segment (SS). The 95\% confidence interval is indicated with ISO 2602:1980.

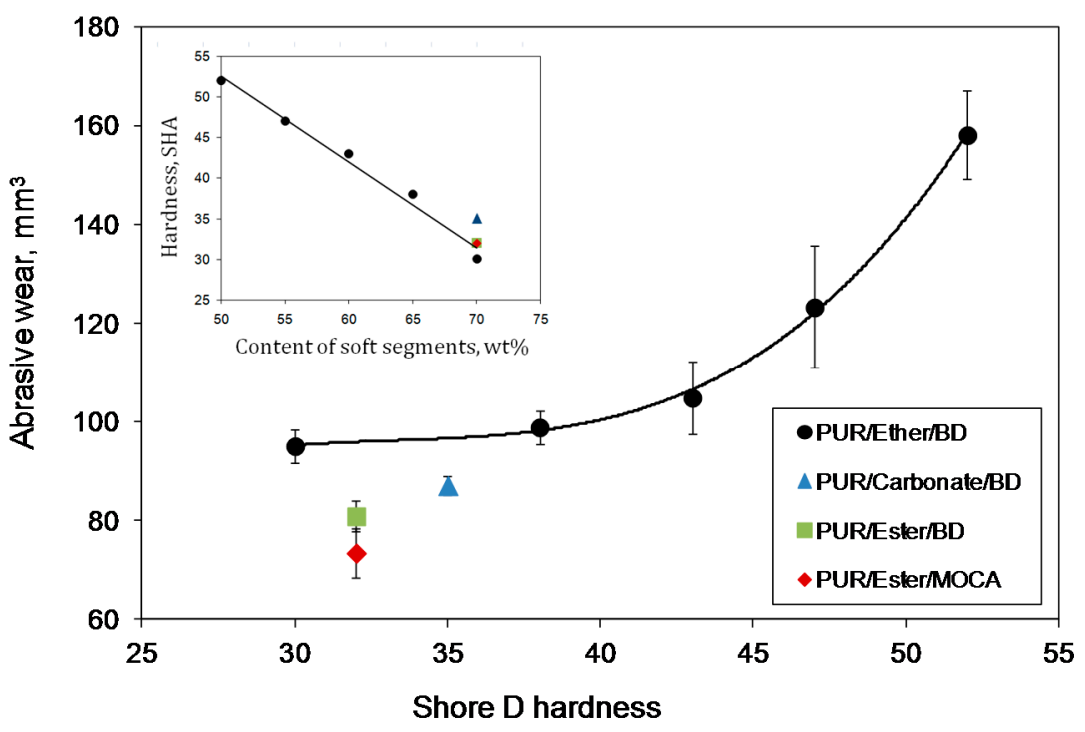

Figure 4. Abrasion wear of PUR versus their hardness.

The abrasive wear of PUR versus their shore D hardness are presented on Figure 4. For the materials with the same chemical composition (PUR/Ether/BD), the following correlation can be defined: a higher content of the SS results in higher wear resistance. However, when different polyols are used, such a correlation is not observed.

The density of prepared PUR is a superposition of the soft phase density derived from SS, the hard phase density derived from HS, and the interphase density. The densities of the polyols used for synthesis in $23{ }^{\circ} \mathrm{C}$ were $0.978 \mathrm{~g} / \mathrm{cm}^{3}$ for polyether, $1.141 \mathrm{~g} / \mathrm{cm}^{3}$ for polycarbonate, and $1.187 \mathrm{~g} / \mathrm{cm}^{3}$ for polyester. In our previous study [22], the density of $1.29 \mathrm{~g} / \mathrm{cm}^{3}$ for the pure hard phase derived from HS (MDI and 1.4 BD) was determined. Based on this data, it was found that the density values of prepared PUR (Table 3) are consistent with the superposition of all phases and their content in the polymers. 
Table 3. The density of prepared PUR. The 95\% confidence interval is indicated with SO2602:1980.

\begin{tabular}{ccc}
\hline Materials & Density, $\mathbf{g} / \mathbf{c m}^{\mathbf{3}}$ & $\mathbf{9 5 \%}$ Confidence interval, $\mathbf{g} / \mathbf{c m}^{\mathbf{3}}$ \\
\hline PUR_50/Ether/BD & 1.1274 & 0.0191 \\
PUR_55/Ether/BD & 1.1158 & 0.0126 \\
PUR_60/Ether/BD & 1.1032 & 0.0070 \\
PUR_65/Ether/BD & 1.0912 & 0.0074 \\
PUR_70/Ether/BD & 1.0740 & 0.0027 \\
PUR_70/Carbonate/BD & 1.1535 & 0.0082 \\
PUR_70/Ester/BD & 1.2416 & 0.0158 \\
PUR_70/Ester/MOCA & 1.2508 & 0.0071 \\
\hline
\end{tabular}

The FTIR spectra for the ether-containing elastomers (Figure 5) indicated that, along with the increase of the SS content, the carbonyl hydrogen bonding index, $R$, is decreasing (Table 4). Specifically, $R$ is defined as the ratio of the amount of carbonyl groups connected by the hydrogen bond $\left(1700 \mathrm{~cm}^{-1}\right)$ to the amount of free carbonyl groups $\left(1730 \mathrm{~cm}^{-1}\right)$. Moreover, while the decrease in the phase separation degree, DPS, is observed, the degree of phase mixing, DPM, is increasing. This means that, in fact, the urethane hard phase domains, presented in the microstructure, are getting smaller. This also reflects the next correlation: smaller or finer hard phase domains and a higher DPM result in higher wear resistance in the case of PUR with polyether SS.

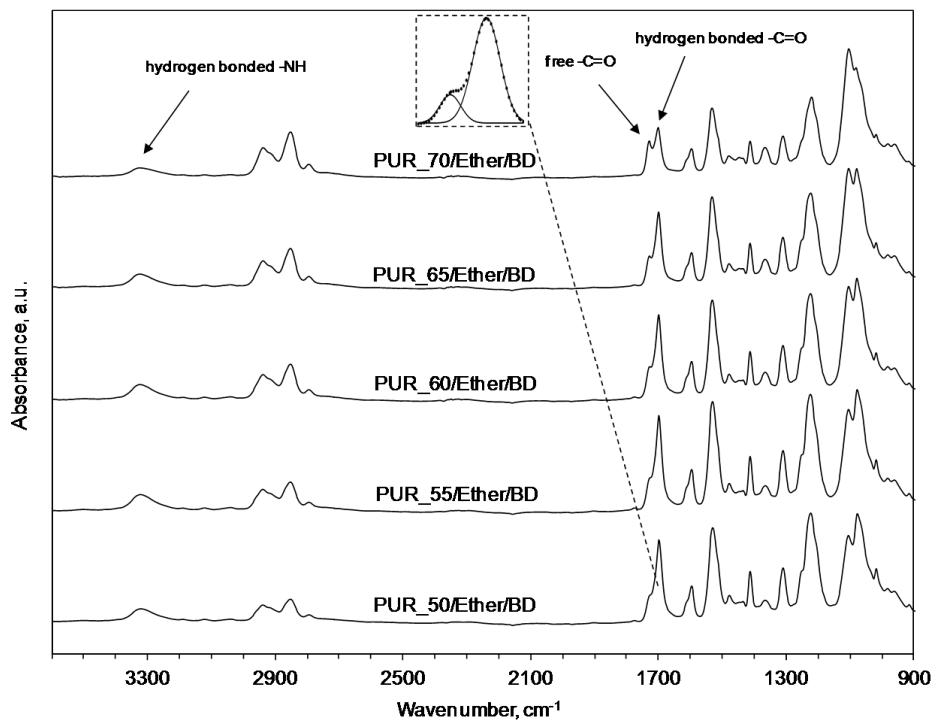

Figure 5. FT-IR spectra of PUR with different content levels of polyether soft segments.

When comparing the FTIR spectra of PUR with the content of $70 \mathrm{wt} \%$ of different soft segments, presented in Figure 6, substantial differences concerning both the hydrogen-bonded and free carbonyl groups are observed as well as differences in the peak related to the $-\mathrm{NH}$ group. If the key factor affecting the abrasive performance of the polymers is the differences in the hydrogen bondings, then it explains our motivation to use the diamine chain extender instead of the butanediol one. Indeed, the amine group, when reacting with the isocyanate, creates the urea group, which is characterized by the presence of $-\mathrm{NH}$ groups bonded symmetrically on both sides of the carbonyl group. The two -NH groups belonging to the urea moiety in the HS result in twice as strong hydrogen bonding compared with the one $-\mathrm{NH}$ group coming from the urethane group. This is reflected by the widening of the peak corresponding to the wave number in the range of $3300-3330 \mathrm{~cm}^{-1}$, and is a consequence of the superposition of two peaks: -NH hydrogen bonding of the urethane group $\left(3330 \mathrm{~cm}^{-1}\right)$ and of the urea group $\left(3300 \mathrm{~cm}^{-1}\right)$. The peak centered at $1640 \mathrm{~cm}^{-1}$ corresponds to the hydrogen-bonded ordered urea carbonyl bond. 


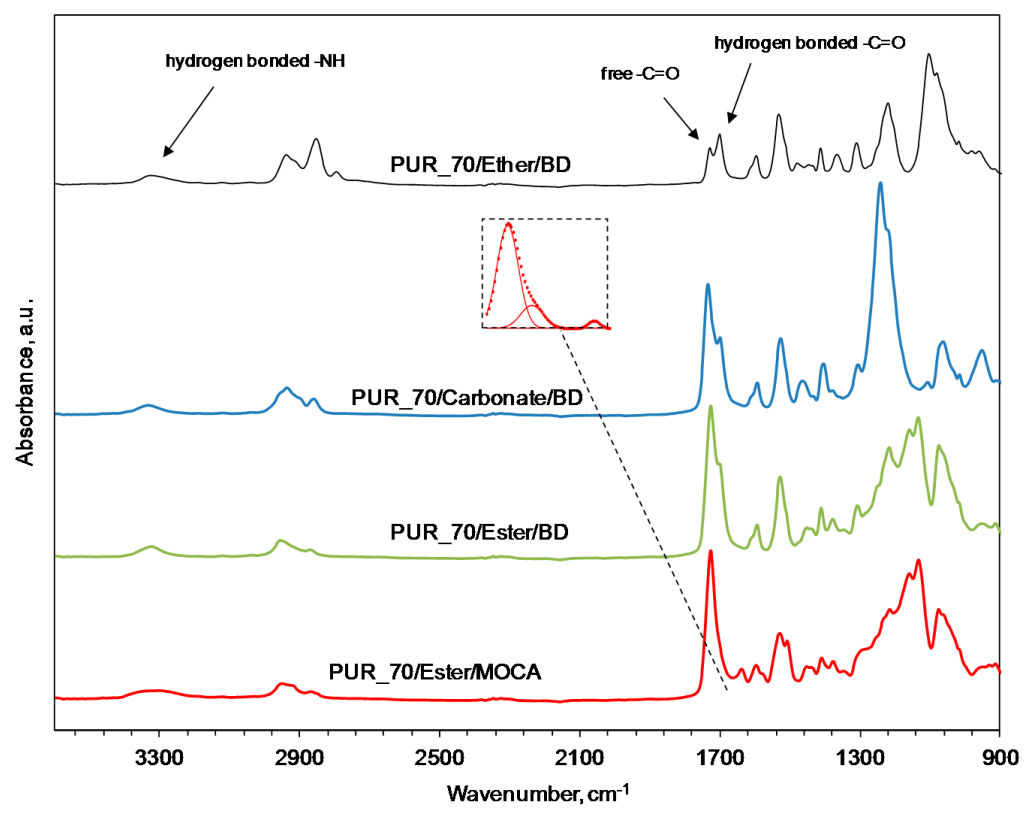

Figure 6. FT-IR spectra of PUR with the various chemical compositions. Contents of the SS for all materials is constant.

Table 4. The carbonyl hydrogen bonding index $(R)$, the degree of the phase separation (DPS), and the degree of the phase mixing $(D P M)$ in the prepared PUR.

\begin{tabular}{cccccc}
\hline Sample & $\boldsymbol{A}_{\mathbf{1 7 3 0}}{ }^{*}$ & $\boldsymbol{A}_{\mathbf{1 7 0 0}}{ }^{* *}$ & $\boldsymbol{R}^{* * *}$ & $\boldsymbol{D P S}$ & $\mathbf{D P M}$ \\
\hline PUR_50/Ether/BD & 1.40 & 6.65 & 4.74 & 0.83 & 0.17 \\
PUR_55/Ether/BD & 1.73 & 7.33 & 4.25 & 0.81 & 0.19 \\
PUR_60/Ether/BD & 1.70 & 6.56 & 3.86 & 0.79 & 0.21 \\
PUR_65/Ether/BD & 1.57 & 5.74 & 3.65 & 0.79 & 0.21 \\
PUR_70/Ether/BD & 1.79 & 3.94 & 2.20 & 0.69 & 0.31 \\
PUR_70/Carbonate/BD & 10.7 & 7.29 & 0.683 & 0.41 & 0.59 \\
PUR_70/Ester/BD & 13.0 & 5.62 & 0.433 & 0.30 & 0.70 \\
PUR_70/Ester/MOCA & 11.7 & $3.21^{+}$ & 0.275 & 0.22 & 0.78 \\
\hline
\end{tabular}

A: absorption intensity calculated as the area of Gaussian multipeak fitting [absorbance * wavenumber]; * $A_{1730}$ : absorption intensity of free carbonyl. ${ }^{* *} A_{1700}$ : absorption intensity of hydrogen-bonded carbonyl. ${ }^{+}$: the sum of the absorption intensities of hydrogen-bonded carbonyl from ester $\left(1700 \mathrm{~cm}^{-1}\right)$ and urea $\left(1640 \mathrm{~cm}^{-1}\right)$. *** $R=A_{1700} / A_{1730}$ : carbonyl hydrogen bonding index.

The wide-angle X-ray diffraction profiles (WAXS) of the polyether-containing PUR in Figure 7 do not show a clear effect of the long-range order related to the crystallization of the HS, regardless of the HS to SS ratio. In the case of the elastomer containing $50 \mathrm{wt} \%$ of soft segments, the peak on the pattern is slightly broader; this is due to the superposition of two constituent peaks, and might be explained as the effect of the simple (primitive) arrangement. However, it declines along with the content of the soft phase. When we compare the WAXS patterns of PUR samples with different SS presented in Figure 8, it is clear that only the PUR material with the polyester segment and BD as the chain extender reveals the effect of the ordered domains. For the same composition but with MOCA being used, the long-range arrangement is not observed. This is consistent with literature data $[10,41-43]$, where MOCA is described as an excellent cross-linker and an outstanding chain extender in polyurethane systems. 


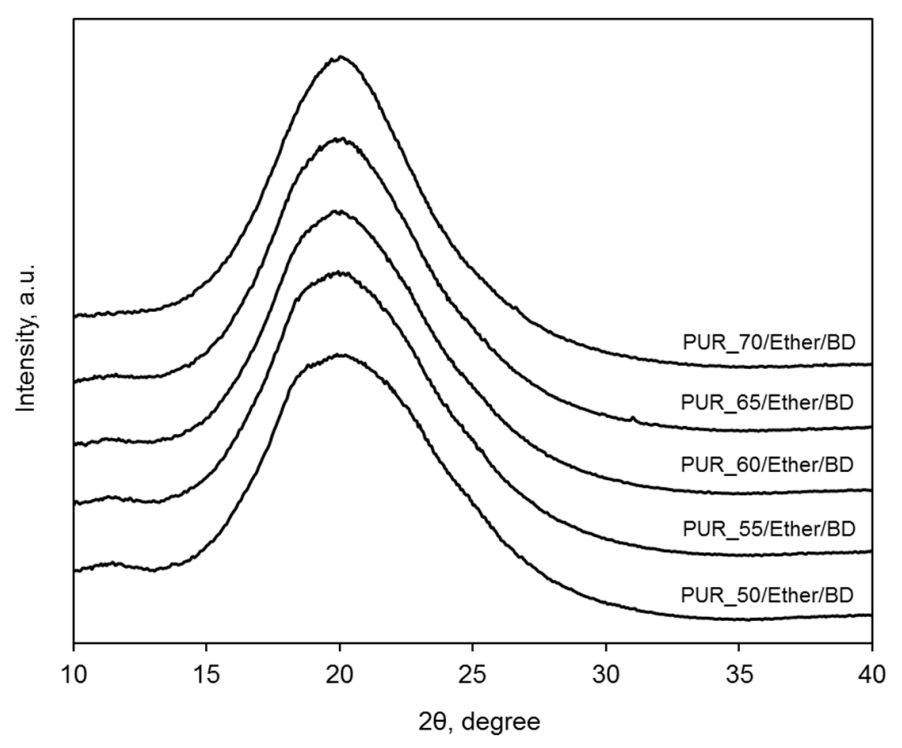

Figure 7. WAXS patterns of PUR with the different contents of the polyether soft segment.

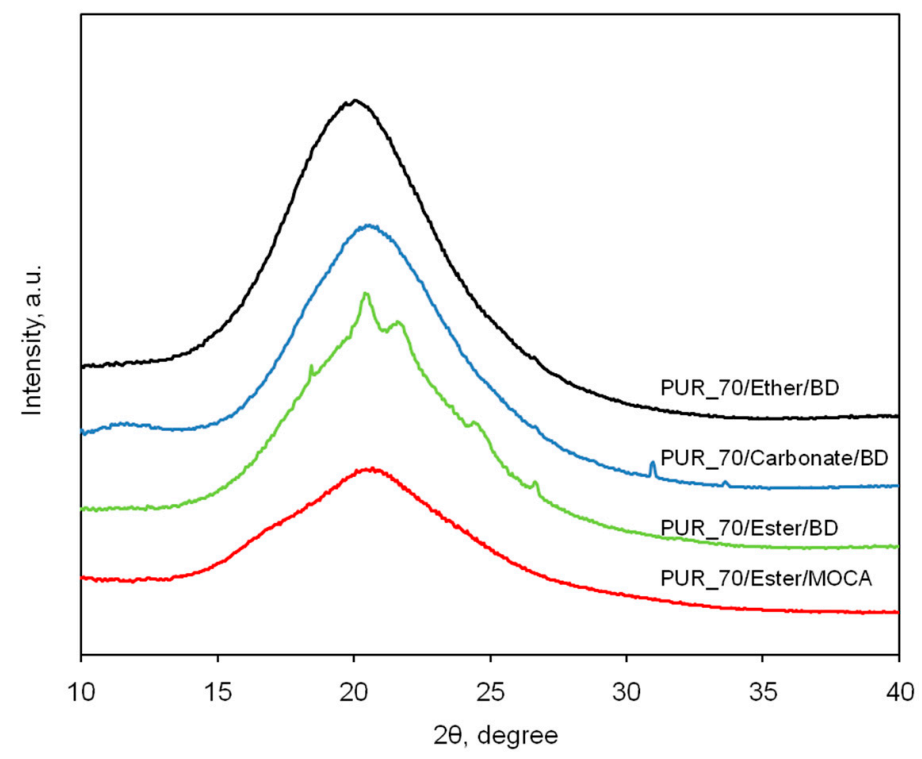

Figure 8. WAXS patterns of PUR with various chemical compositions. Contents of the soft segment for all materials is constant (SS $=70 \mathrm{wt} \%)$.

In order to verify if the crystalline phase in the PUR microstructure is formed by HS or SS, DSC analysis has been employed, and the traces are shown in Figure 9. In the case of the polyether-based elastomers, PTMO segments of $M_{n}=2000 \mathrm{~g} / \mathrm{mol}$ make a soft phase exhibiting the glass transition in the temperature range of $-73^{\circ} \mathrm{C}$ (PUR_50/Ether/BD) to $-67^{\circ} \mathrm{C}$ (PUR_70/Ether/BD); however, a part of this phase is also crystallized giving small melting endotherms between $0{ }^{\circ} \mathrm{C}$ (PUR_50/Ether/BD) and $5{ }^{\circ} \mathrm{C}$ (PUR_70/Ether/BD). Obviously, the effect of the glass transition is more pronounced as the soft phase content increases due to more significant changes of the specific heat. Similarly, the lower the content of the HS, the lower are both the melting temperature of the hard phase and the specific heat of this phase transition. Although the ordered domains giving clear WAXS reflections have not been detected for PTMO-based polyurethanes in the whole range of PTMO content, the DSC analysis reveals the evident endothermal effects assigned to the crystals melting during heating. 


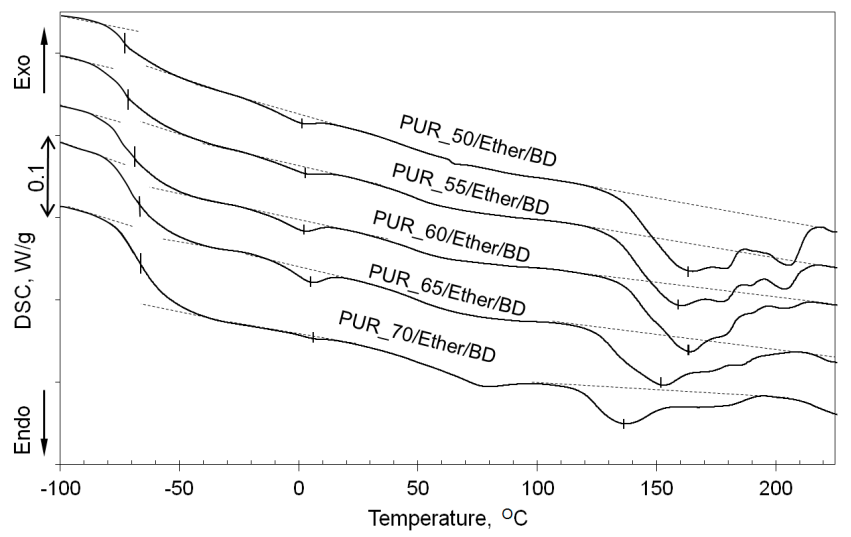

Figure 9. DSC curves of PUR with different contents of the polyether soft segment. First heating.

The DSC thermograms of PUR elastomers with various polyols (Figure 10) indicate the clear melting endotherm of the polyester soft phase when BD is used as the chain extender (PUR_70/Ester/BD). This proves that the diffraction peaks observed on the WAXS profiles are associated with the soft phase. What is interesting is that the same elastomer-containing diamine does not reveal the melting effect of the soft phase, nor the melting of the hard phase which indicates cross-linking of the material. Moreover, it is consistent with the literature data $[10,40-42]$ where MOCA is described as an excellent cross-linker.

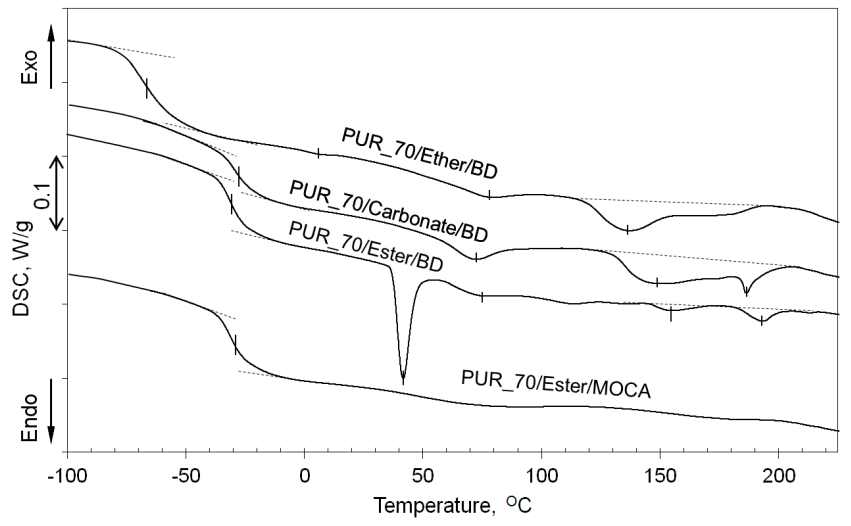

Figure 10. DSC curves of PUR with various chemical composition. Contents of the soft segment for all materials is constant $(\mathrm{SS}=70 \%)$. First heating.

\section{Conclusions}

In this paper, a range of segmented linear polyurethane elastomers containing polyether, polycarbonate, and polyester polyols as the soft segments were synthesized and characterized. The main purpose was to study the effect of the polyol chemical structure and the content on the abrasive wear resistance of PUR materials in order to explain the origin of their different wear performances. It was confirmed that the higher the content of the soft phase in a PUR sample, the higher the wear resistance. This results in a better phase mixing (higher DPM value) in the microstructure. As a consequence, the hard phase domains are smaller or finer and the interfacial area to volume ratio is increasing. These findings became the motivation to continue the studies on PUR elastomers containing $70 \mathrm{wt} \%$ of various polyols. The abrasion tests revealed that the polyester soft phase seems to be the most effective in improving the abrasive wear resistance if compared with the polyether and polycarbonate phases. This is explained by the higher cohesion of the polyester phase, because the carbonyl group in ester bonding makes much stronger hydrogen bonds than the ether group. 
It was also concluded that the crystallization ability is not critical for the abrasion wear performance. As the most promising material, we used the polyester-based PUR with the diamine chain extender. The tested sample revealed melting endotherm neither of the soft nor of the hard phase. This is most likely the reason that the calculated degree of phase mixing $(D P M)$ is the highest for the selected material.

Acknowledgments: This work was financially supported by National Science Centre in Poland, project Preludium 2015/19/N/ST8/01928. We thank Magdalena Kwiatkowska and Krzysztof Rucki (BEng) for providing the language support and the proof reading of this article.

Author Contributions: Konrad Kwiatkowski conceived and designed the experiments; Małgorzata Nachman performed the experiments; Konrad Kwiatkowski and Małgorzata Nachman analyzed the data; Konrad Kwiatkowski and Małgorzata Nachman wrote the paper.

Conflicts of Interest: The authors declare no conflict of interest.

\section{References}

1. Stachowiak, G.W.; Batchelor, A.W. 16-wear of non-metallic materials. In Engineering Tribology, 3rd ed.; Butterworth-Heinemann: Butterworth-Heinemann, Burlington, 2006; pp. 651-704.

2. Bayer, R.G. Mechanical Wear Prediction and Prevention; Marcel Dekker: New York, NY, USA, 1994.

3. Ashby, M.F.; Jones, D.R.H. Materiaty Inżynierskie. Właścizoości I Zastosowania; WNT: Warszawa, Poland, 1995.

4. Bhushan, B. Principles and Applications of Tribology; John Wiley \& Sons: New York, NY, USA, 1999.

5. Moore, D.F. The Friction and Lubrication of Elastomers; Pergamon Press: Oxford, UK, 1972.

6. Brostow, W.; Deborde, J.-L.; Jaklewicz, M.; Olszynski, P. Tribology with emphasis on polymers: Friction, scratch resistance and wear. J. Mater. Educ. 2003, 24, 119-132.

7. Brostow, W.; Kovačević, V.; Vrsaljko, D.; Whitworth, J. Tribology of polymers and polymer based composites. J. Mater. Educ. 2010, 32, 273-290.

8. Trofimovich, A.N.; Anisimov, V.N.; Kurachenkov, V.N.; Strakhov, V.V.; Letunovskii, M.P.; Egorov, S.F. Role of structure factor in evaluating polyurethane wear resistance. Sov. J. Frict. Wear 1987, 8, 87-92.

9. Semenets, A.A.; Anisimov, V.N. Development of triboengineering composite materials based on thermoplastic polyurethanes. J. Frict. Wear 2010, 31, 208-213. [CrossRef]

10. Beck, R.A.; Truss, R.W. Effect of chemical structure on the wear behaviour of polyurethane-urea elastomers. Wear 1998, 218, 145-152. [CrossRef]

11. Zhou, R.; Lu, D.H.; Jiang, Y.H.; Li, Q.N. Mechanical properties and erosion wear resistance of polyurethane matrix composites. Wear 2005, 259, 676-683. [CrossRef]

12. Sare, I.R.; Mardel, J.I.; Hill, A.J. Wear-resistant metallic and elastomeric materials in the mining and mineral processing industries-An overview. Wear 2001, 250, 1-10. [CrossRef]

13. Jia, X.; Ling, R. Two-body free-abrasive wear of polyethylene, nylon1010, expoxy and polyurethane coatings. Tribol. Int. 2007, 40, 1276-1283. [CrossRef]

14. Wirpsza, Z. Poliuretany. Chemia, Technologia, Zastosowanie; WNT: Warszawa, Poland, 1991.

15. Prociak, A.; Rokicki, G.; Ryszkowska, J. Materiaty Poliuretanowe; WNT: Warszawa, Poland, 2014.

16. Prisacariu, C. Polyurethane Elastomers: From Morphology to Mechanical Aspect; Springer: New York, NY, USA, 2011.

17. Król, P. Synthesis methods, chemical structures and phase structures of linear polyurethanes. Properties and applications of linear polyurethanes in polyurethane elastomers, copolymers and ionomers. Prog. Mater. Sci. 2007, 52, 915-1015. [CrossRef]

18. Rabinowicz, E. Friction and Wear of Materials, 2nd ed.; Wiley: New York, NY, USA, 1995.

19. Anisimov, V.N.; Semenets, A.A.; Letunovskii, M.P.; Strakhov, V.V. Effect of rigid blocks on the mechanical characteristics and abrasive resistance of polyurethanes. Mater. Sci. 2002, 38, 95-98. [CrossRef]

20. Ryszkowska, J. Supermolecular structure, morphology and physical properties of urea-urethane elastomers. Polimery 2012, 57, 775-902. [CrossRef]

21. Nachman, M.; Kwiatkowski, K. The effect of thermal annealing on the abrasion resistance of a segmented block copolymer urethane elastomers. Wear 2013, 306, 113-118. [CrossRef] 
22. Michalski, P.; Nachman, M.; Kwiatkowski, K. Abrasive wearofurethane elastomers based on monomeric or polymeric diisocyanate mdi. Polimery 2012, 57, 839-845. [CrossRef]

23. Kwiatkowski, K.; Rosłaniec, Z. The relationship between hardness and abrasive wear resistance. In Proceedings of the Materiały Polimerowe Pomerania Plast 2010, Szczecin, Poland, 7-10 June 2016; pp. 387-390.

24. Kojio, K.; Nakashima, S.; Furukawa, M. Microphase-separated structure and mechanical properties of norbornane diisocyanate-based polyurethanes. Polymer 2007, 48, 997-1004. [CrossRef]

25. Velankar, S.; Cooper, S.L. Microphase separation and rheological properties of polyurethane melts. 1. Effect of block length. Macromolecules 1998, 31, 9181-9192. [CrossRef]

26. Velankar, S.; Cooper, S.L. Microphase separation and rheological properties of polyurethane melts. 2. Effect of block incompatibility on the microstructure. Macromolecules 2000, 33, 382-394. [CrossRef]

27. Nachman, M.; Kwiatkowski, K. The effect of annealing temperature on the phase structure of multiblock urethane elastomers. Przem. Chem. 2013, 92, 2010-2012.

28. Tocha, E.; Janik, H.; Debowski, H.; Vancso, G.J. Morphology of polyurethanes revisited by complementary afm and tem. J. Macromol. Sci. Part B 2002, 41, 1291-1304. [CrossRef]

29. Król, P.; Pilch-Pitera, B. Phase structure and thermal stability of crosslinked polyurethane elastomers based on well-defined prepolymers. J. Appl. Polym. Sci. 2007, 104, 1464-1474. [CrossRef]

30. Janik, H.; Vancso, J. The influence of hard segment crosslinking on the morphology and mechanical properties of segmented poly(ester-urethanes). Polimery 2005, 2, 139-142.

31. Bagdi, K.; Molnár, K.; Sajó, I.; Pukánszky, B. Specific interactions, structure and properties in segmented polyurethane elastomers. Express Polym. Lett. 2011, 5, 417-427. [CrossRef]

32. Sonnenschein, M.F.; Lysenko, Z.; Brune, D.A.; Wendt, B.L.; Schrock, A.K. Enhancing polyurethane properties via soft segment crystallization. Polymer 2005, 46, 10158-10166. [CrossRef]

33. Eceiza, A.; de la Caba, K.; Kortaberria, G.; Gabilondo, N.; Marieta, C.; Corcuera, M.A.; Mondragon, I. Influence of molecular weight and chemical structure of soft segment in reaction kinetics of polycarbonate diols with 4,4'-diphenylmethane diisocyanate. Eur. Polym. J. 2005, 41, 3051-3059. [CrossRef]

34. Hernandez, R.; Weksler, J.; Padsalgikar, A.; Choi, T.; Angelo, E.; Lin, J.S.; Xu, L.-C.; Siedlecki, C.A.; Runt, J. A comparison of phase organization of model segmented polyurethanes with different intersegment compatibilities. Macromolecules 2008, 41, 9767-9776. [CrossRef]

35. Rueda-Larraz, L.; Fernandez d'Arlas, B.; Tercjak, A.; Ribes, A.; Mondragon, I.; Eceiza, A. Synthesis and microstructure-mechanical property relationships of segmented polyurethanes based on a PCL-PTHF-PCL block copolymer as soft segment. Eur. Polym. J. 2009, 45, 2096-2109. [CrossRef]

36. Garrett, J.T.; Xu, R.; Cho, J.; Runt, J. Phase separation of diamine chain-extended poly(urethane) copolymers: Ftir spectroscopy and phase transitions. Polymer 2003, 44, 2711-2719. [CrossRef]

37. Pretsch, T.; Jakob, I.; Müller, W. Hydrolytic degradation and functional stability of a segmented shape memory poly(ester urethane). Polym. Degrad. Stab. 2009, 94, 61-73. [CrossRef]

38. Seymour, R.W.; Estes, G.M.; Cooper, S.L. Infrared studies of segmented polyurethan elastomers. I. Hydrogen bonding. Macromolecules 1970, 3, 579-583. [CrossRef]

39. Coleman, M.M.; Skrovanek, D.J.; Hu, J.; Painter, P.C. Hydrogen bonding in polymer blends. 1. Ftir studies of urethane-ether blends. Macromolecules 1988, 21, 59-65. [CrossRef]

40. Ayres, E.; Oréfice, R.L.; Yoshida, M.I. Phase morphology of hydrolysable polyurethanes derived from aqueous dispersions. Eur. Polym. J. 2007, 43, 3510-3521. [CrossRef]

41. Xiong, J.; Zheng, Z.; Song, W.; Zhou, D.; Wang, X. Microstructure and properties of polyurethane nanocomposites reinforced with methylene-bis-orthochloroanilline-grafted multi-walled carbon nanotubes. Compos. A Appl. Sci. Manuf. 2008, 39, 904-910. [CrossRef]

42. Demarest, C. Life beyond moca. In Proceedings of the the Polyurethane Manufacturers Association Annual Meeting Phoenix, Las Vegas, NV, USA, 5-8 May 2014.

43. Lamba, N.M.K.; Woodhouse, K.A.; Cooper, S.L. Polyurethanes in Biomedical Application; CRC Press: New York, NY, USA, 1997.

(C) 2017 by the authors. Licensee MDPI, Basel, Switzerland. This article is an open access article distributed under the terms and conditions of the Creative Commons Attribution (CC BY) license (http:/ / creativecommons.org/licenses/by/4.0/). 